\title{
Hubungan Kepuasan Pasien Dengan Minat Menggunakan pelayanan Kesehatan di Puskesmas.
}

\author{
Refi Andi Alamsyah,., , Ekowati Retnaningtyas, , Nining Loura Sari, a \\ ${ }^{a}$ Prodi Sarjana Keperawatan, STIKes Maharani, Malang, Indonesia \\ ${ }^{\mathrm{b}}$ Prodi Sarjana Keperawatan, Poltekkes Kemenkes, Malang, Indonesia
}

Email Korespondensi: refiandiial@gmail.com

\begin{abstract}
Introduction: Health services at Puskesmas currently demand quality improvement. The quality of health services is closely related to satisfaction. Consumers who are satisfied with the services will tend to keep using the health services in the future. The purpose of this study was to determine the correlation between satisfaction level of patients and their interest in using health services in Puskesmas Dinoyo, Malang city.Methode: This research is a descriptive study with cross sectional design. Samples were 50 patients seeking treatment in Puskesmas Dinoyo, Malang city, who were selected by using total sampling. The data were retrieved from the respondents by filling out questionnaires. The results of the study were presented in a distribution table and were analyzed statistically, in order to see whether there is a correlation between independent and dependent variables. Result:. The test results with $\rho=0.05$ obtained $\rho=0.00$ with correlation coefficient $r=$ 0.480 . This result indicated a significant correlation. This means that the higher the satisfaction level of patients, the higher the interest of patient in keeping to use the health services at the Puskesmas is. Conclucion: Based on the results, further research is expected to be carried out by expanding the variables that can influence patient interest in using health services.
\end{abstract}

Keywords: patient satisfaction, patient interest and health services.

\begin{abstract}
Abstrak
Pendahuluan: Pelayanan jasa kesehatan yang ada di Puskesmas saat ini menuntut peningkatan mutu. Mutu pelayanan kesehatan sangat terkait dengan kepuasan. Konsumen yang puas akan jasa yang diterimanya akan cenderung menggunakan jasa pelayanan kesehatan dimasa yang akan datang. Tujuan Penelitian untuk mengetahui hubungan tingkat kepuasan pasien dengan minat menggunakan jasa pelayanan kesehatan di Puskesmas Dinoyo-Malang. Metode: Penelitian ini merupakan penelitian deskriptif dengan rancangan cross sectional. Sampel diambil dari pasien yang berobat di Puskesmas Dinoyo-Malang sebanyak 50 sampel, dengan menggunakan total sampling. Pengambilan data melalui pengisian kuesioner oleh responden. Hasil: penelitian disajikan dalam bentuk tabel distribusi dengan di analisa secara statistik, untuk melihat ada tidaknya hubungan antara variabel independen dan dependen. Hasil pengujian dengan $\square=0,05$ didapatkan $\square=0,00$ dengan koefisien korelasi $r=0.480$, indikasi ini menunjukkan yang signifikan. Artinya semakin tinggi tingkat kepuasan pasien maka minat mereka untuk kembali menggunakan jasa pelayanan kesehatan di Puskesmas tersebut juga akan cenderung semakin tinggi. Kesimpulan: Berdasarkan hasil diatas diharapkan diadakan penelitian lanjutan dengan memperluas variabel yang dapat mempengaruhi minat pasien menggunakan jasa pelayanan kesehatan.
\end{abstract}

Kata kunci : kepuasan pasien, minat pasien dan pelayanan jasa kesehatan. 
PROFESIONAL HEALTH JOURNAL

Volume2, No. 2, Juni 2021 (Hal. 101-111)

https://www.ojsstikesbanyuwangi.com/index.php/PHJ

\section{PENDAHULUAN}

Salah satu aspek yang sangat penting dalam kehidupan manusia adalah kesehatan. Manusia kebanyakan akan melakukan berbagai cara untuk memperoleh kesehatan yang prima (Amin et al., 2018). Orang yang sedang menderita sakit biasanya akan berusaha untuk mengatasi dan mengobati penyakit yang dideritanya hingga dia sembuh (Adisasmito, 2009).

Untuk meningkatkan kesehatan masyarakat adalah dengan terus meningkatkan kualitas penyedia pelayanan publik bidang kesehatan di Malang, salah satunya dengan meningkatkan pelayanan dasar bagi masyarakat melalui Pusat Kesehatan Masyarakat (Puskesmas). Puskesmas Dinoyo Kota Malang adalah salah satu sarana milik Pemerintah Kota Malang yang merupakan pusat pelayanan yang mempunyai fungsi utama dalam penyembuhan, pemulihan dan sarana kesehatan masyarakat di daerah sekitar Menurut (KEMENKES RI No.128/MENKES/SK/II/2004).

Kepuasan pasien dalam pelayanan kesehatan adalah tingkat perasaan seseorang setelah membandingkan kinerja produk atau hasil yang pasien rasakan dengan harapannya (Damayanti, 2019). Dengan konsumen merasa puas terhadap suatu penggunaan jangka panjang, sebab rasa puas konsumen akan mempengaruhi tindakan yang didasarkan pada pengalaman masa lalu dimana selanjutnya mereka tidak akan mudah berpindah jasa karena stimulasi pemasaran (Maria, 2009).

Minat pasien timbul, disebabkan oleh tersedianya produk/jasa yang lengkap, mutu pelayanan yang baik, kelengkapan alat medis dan pemeriksaan, lokasi mudah dijangkau serta kemudahan transpotasi yang merupakan komponen unsur sarana dan prasarana. Oleh karena itu Rumah Sakit/Puskesmas dituntut untuk mampu mengelolah secara efektif dan efisien sehingga dapat memberikan kepuasan bagi para pelanggannya (Maria, 2009).

\section{METODE}

Penelitian ini merupakan penelitian lapangan yang dilaksanakan dengan menggunakan metode deskriptif korelasional dengan rancangan Cross sectional dan menggunakan instrument kuesioner kepada pasien yang berkunjung untuk berobat di Puskesmas.

1. Deskriptif korelasional yaitu menggambarkan hubungan kepuasan pasien dan pengaruhnya terhadap minat menggunakan jasa pelayanan kesehatan.

2. Cross sectional karena dilakukan observasi atau pengukuran variabel independen dan dependen hanya satu kali.

Populasi, adalah keseluruhan subyek penelitian yang akan diteliti, penelitian ini adalah pasien yang berobat berjumlah 100 orang.

Sampel, adalah bagian dari jumlah dan karakteristik yang dimiliki oleh populasi, karena beberapa hal seperti masalah waktu, tenaga dan biaya maka penelitian ini menggunakan 50 sampel.

Pengumpulan data, dilakukan dengan menyebar kuesioner kepada pasien yang berkunjung untuk berobat di Puskesmas, Kuesioner terdiri dari lima dimensi 


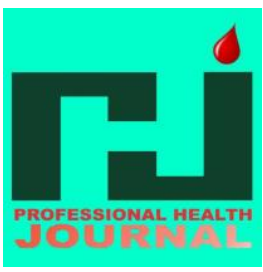

didalam mutu pelayanan jasa kesehatan yaitu Daya Tanggap (responsiveness), Jaminan (assurance), Bukti Langsung (tangibles), Empati (empathy) dan Keandalan (reliability)

Pengolahan Data, dengan 4 tahapan yaitu Pemeriksaan data, Pemberian kode, Pemberian nilai pada beberpa variabel dan Menganalisa data.

Data umum yang diperlukan yaitu berupa karakteristik responden antara lain Umur, Jenis Kelamin, Pendidikan, Pekerjaan dan Riwayat Pelayanan, keragaman karakteristik responden ini dapat mempengaruhi tingkat kepuasan pasien terhadap jasa pelayanan kesehatan dan minat pasien menggunakan jasa pelayanan kesehatan di Puskesmas.

\section{HASIL}

Hasil dari penelitian yang berobat ke Puskesmas sesuai dengan karakteristik responden adalah sebagai berikut :

Tabel 1. Distribusi Karakteristik Umur Responden
\begin{tabular}{|c|c|c|c|c|}
\hline No & Umur & $\begin{array}{c}\text { Usia } \\
\text { responden }\end{array}$ & Frekuensi & $\begin{array}{c}\text { Persentase } \\
(\%)\end{array}$ \\
\hline 1 & Remaja Akhir & $21-30$ Tahun & 30 & $60 \%$ \\
\hline 2 & Dewasa Awal & $31-40$ Tahun & 9 & $18 \%$ \\
\hline 3 & Dewasa Akhir & $41-50$ Tahun & 6 & $12 \%$ \\
\hline 4 & Lansia Awal & $51-60$ Tahun & 5 & $10 \%$ \\
\hline $\begin{array}{l}\text { Total } \\
\text { Sumber karakteristik data primer 2017 }\end{array}$ & 50 & $100 \%$ \\
\hline
\end{tabular}

Berdasarkan tabel 1 diatas diketahui bahwa mayoritas responden $(60 \%)$ berusia antara 21 - 30 tahun.

Tabel 2. Distribusi Karakteristik Jenis Kelamin Responden

\begin{tabular}{|c|c|c|}
\hline $\begin{array}{c}\text { Jenis } \\
\text { Kelamin }\end{array}$ & Frekuensi & $\begin{array}{c}\text { Persentase } \\
(\%)\end{array}$ \\
\hline Pria & 24 & 48 \\
\hline Wanita & 26 & 52 \\
\hline Total & 50 & 100 \\
\hline
\end{tabular}

PROFESIONAL HEALTH JOURNAL

Volume2, No. 2, Juni 2021 (Hal. 101-111) https://www.ojsstikesbanyuwangi.com/index.php/PHJ

Berdasarkan tabel 2 diatas diketahui bahwa mayoritas responden (52\%) berjenis kelamin wanita.

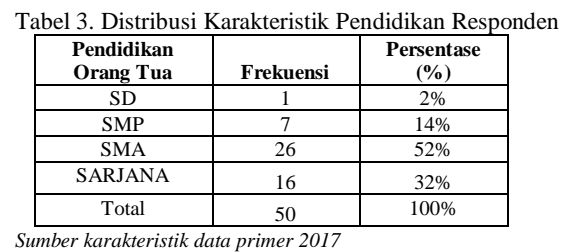

Berdasarkan tabel 3 diatas diketahui bahwa sebagian besar responden $(52 \%)$ berpendidikan SLTA.

Tabel 4. Distribusi Karakteristik Jenis Pekerjaan Responden
\begin{tabular}{|c|c|c|}
\hline $\begin{array}{c}\text { Pekerjaan } \\
\text { Responden }\end{array}$ & Frekuensi & $\begin{array}{c}\text { Persentase } \\
(\%)\end{array}$ \\
\hline PNS & 1 & $2 \%$ \\
\hline ABRI & 0 & $0 \%$ \\
\hline Swasta & 13 & $26 \%$ \\
\hline Lain-lain & 36 & $72 \%$ \\
\hline Total & 50 & $100 \%$ \\
\hline
\end{tabular}
Sumber karakteristik data primer 2017

Berdasarkan tabel 4 diatas diketahui bahwa mayoritas (72\%) Jenis Pekerjaan LainLain.

Tabel 5. Distribusi Karakteristik Riwayat Pelayanan Responden
\begin{tabular}{|c|c|c|}
\hline $\begin{array}{c}\text { Riwayat } \\
\text { Pelayanan }\end{array}$ & Frekuensi & $\begin{array}{c}\text { Persentase } \\
(\%)\end{array}$ \\
\hline Belum Pernah & 7 & $14 \%$ \\
\hline Satu Kali & 10 & $20 \%$ \\
\hline Dua Kali & 15 & $30 \%$ \\
\hline Lebih Dua Kali & 18 & $36 \%$ \\
\hline Total & 50 & $100 \%$ \\
\hline
\end{tabular}
Sumber karakteristik data primer 2017

Berdasarkan tabel 5 diatas diketahui bahwa mayoritas responden $(30 \%)$ berobat sebanyak Dua Kali di Puskesmas Dinoyo, Malang. 
PROFESIONAL HEALTH JOURNAL

Volume2, No. 2, Juni 2021 (Hal. 101-111)

https://www.ojsstikesbanyuwangi.com/index.php/PHJ

Hasil Penelitian kepuasan responden yang berobat di Puskesmas Dinoyo Malang, ditunjukkan dalam gambar dibawah ini :

Gambar 5.6. Grafik Kategori Tingkat Kepuasan Pasien

Berdasarkan gambar di atas diketahui bahwa sebagian responden menyatakan tingkat kepuasan Sedang sejumlah $52 \%$, kepuasan Tinggi 48\% dan kepuasan Rendah $0 \%$

Hasil analisa variabel Kepuasan Responden berdasarkan 5 Dimensi, disajikan tabel dibawah ini :

\begin{tabular}{|l|l|l|l|l|l|l|}
\hline \multirow{2}{*}{ Kepuasan Pasien } & \multicolumn{2}{|c|}{ Rendah } & \multicolumn{2}{c|}{ Sedang } & \multicolumn{2}{c|}{ Tinggi } \\
\cline { 2 - 8 } & $\Sigma$ & $\%$ & $\Sigma$ & $\%$ & $\Sigma$ & $\%$ \\
\hline Bukti Langsung (tangibles) & 0 & $0 \%$ & 33 & $66 \%$ & 17 & $34 \%$ \\
\hline Keandalan (Reliability) & 1 & $2 \%$ & 30 & $60 \%$ & 19 & $38 \%$ \\
\hline Daya Tanggap (Responsiveness) & 0 & $0 \%$ & 36 & $72 \%$ & 14 & $28 \%$ \\
\hline Jaminan (Assurance) & 0 & $0 \%$ & 31 & $62 \%$ & 19 & $38 \%$ \\
\hline Empati (Empathy) & 2 & $4 \%$ & 44 & $88 \%$ & 48 & $8 \%$ \\
\hline Sumber Data Primer 2017 & & & & &
\end{tabular}

Melalui pengelompokan kategori berdasarkan dimensi dari tingkat kepuasan pasien berobat di Puskesmas Dinoyo Malang. diatas, maka dapat diketahui bahwa mayoritas sebanyak $66 \%$ pasien merasa bahwa kepuasan mereka berkenaan dengan dimensi Bukti Langsung (tangibles) tergolong Sedang 60\% pasien merasa bahwa kepuasan mereka berkaitan dengan Keandalan (Reliability) tergolong
Sedang, sebanyak $72 \%$ pasien merasa bahwa Daya Tanggap (responsiveness)

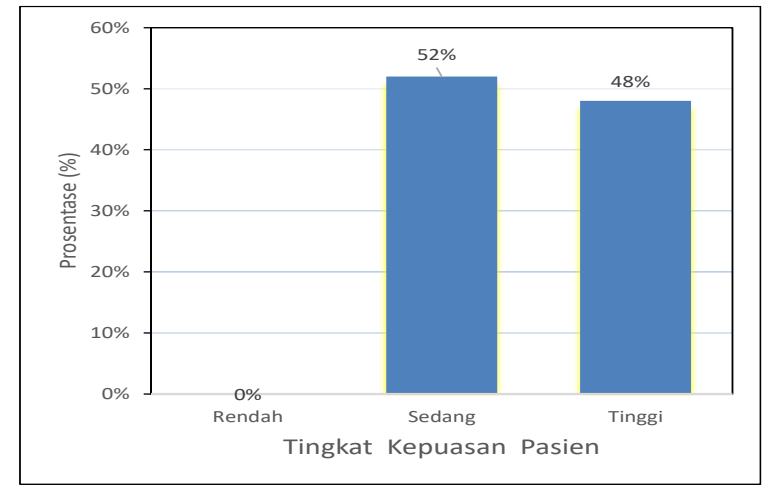

petugas tergolong Sedang, sebanyak 62\% pasien merasa bahwa kepuasan mereka terhadap Jaminan (Assurance) tergolong Sedang dan sebanyak $88 \%$ pasien merasa bahwa kepuasan mereka terhadap Empati (empathy) petugas tergolong Sedang. Sedangkan pasien lainnya mempunyai tingkat kepuasan pada pelayanan kesehatan dari para petugas di Puskesmas Dinoyo, Malang yang cukup bervariasi.

Berdasarkan hasil jawaban tentang minat pasien yang menggunakan jasa pelayanan kesehatan ditunjukkan dalam gambar dibawah ini : 

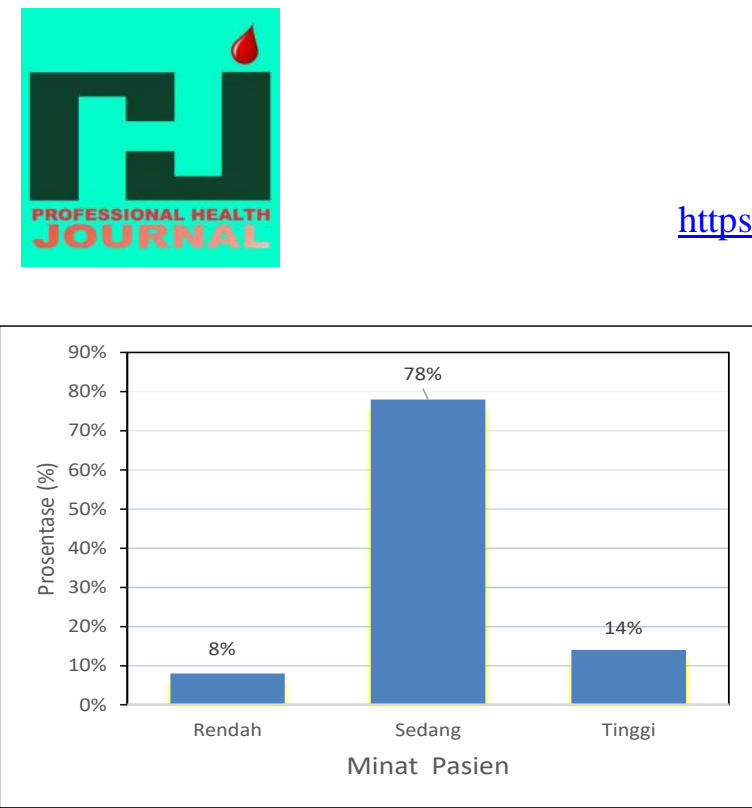

Gambar 5.7. Grafik Kategori Minat

Berdasarkan gambar 5.7 diatas diketahui bahwa sebanyak $78 \%$ para pasien mempunyai minat yang tergolong Sedang untuk menggunakan pelayanan jasa kesehatan di Puskesmas Dinoyo- Malang, bahkan $14 \%$ pasien mempunyai Minat yang tergolong Tinggi dan hanya $8 \%$ pasien mempunyai Minat rendah untuk menggunakan jasa pelayanan kesehatan di Puskesmas tersebut.

Hubungan Kepuasan dengan Minat menggunakan jasa pelayanan kesehatan yaitu dengan menggunakan uji korelasi
PROFESIONAL HEALTH JOURNAL

Volume2, No. 2, Juni 2021 (Hal. 101-111) https://www.ojsstikesbanyuwangi.com/index.php/PHJ

Spearman. Seperti yang ada dalam tabel dibawah ini :

\begin{tabular}{|c|c|c|c|c|c|c|c|c|}
\hline & \multicolumn{8}{|c|}{ Minat Pasien } \\
\hline & \multicolumn{2}{|c|}{ Rendah } & \multicolumn{2}{|c|}{ Sedang } & \multicolumn{2}{|c|}{ Tinggi } & \multicolumn{2}{|c|}{ Total } \\
\hline & Frekw & $\%$ & Frekw & $\%$ & Frekw & $\%$ & Frekw & $\%$ \\
\hline Sedang & 4 & $8 \%$ & 22 & $44 \%$ & 0 & $0 \%$ & 26 & $52 \%$ \\
\hline Tinggi & 0 & $0 \%$ & 17 & $34 \%$ & 7 & $14 \%$ & 24 & $48 \%$ \\
\hline Total & 4 & $8 \%$ & 39 & $78 \%$ & 7 & $14 \%$ & 50 & $100 \%$ \\
\hline \multicolumn{9}{|c|}{ Uji Spearman Rho C } \\
\hline
\end{tabular}

Berdasarkan Tabel 5.2. diatas dapat terlihat bahwa rata-rata jumlah responden dengan tingkat kepuasan sedang sehingga mempunyai tingkatan minat yang sedang pula. Pasien yang mempunyai kepuasan rendah sehingga menyebabkan minat mereka menjadi rendah untuk kembali menggunakan jasa pelayanan kesehatan di Puskesmas

Sehingga dapat dikatakan bahwa semakin tinggi tingkat kepuasan pasien terhadap jasa pelayanan kesehatan di Puskesmas Dinoyo, Malang. maka minat mereka untuk kembali menggunakan jasa pelayanan kesehatan di Puskesmas tersebut juga akan cenderung semakin tinggi. Sebaliknya semakin rendah tingkat kepuasan pasien terhadap jasa pelayanan kesehatan di Puskesmas Dinoyo Malang, maka minat mereka untuk kembali menggunakan jasa pelayanan kesehatan di Puskesmas tersebut juga kan cenderung semakin rendah. 
PROFESIONAL HEALTH JOURNAL

Volume2, No. 2, Juni 2021 (Hal. 101-111)

https://www.ojsstikesbanyuwangi.com/index.php/PHJ

Berdasarkan Tabel di atas menunjukkan nilai koesfisien korelasi rho spearman untuk hubungan antara tingkat kepuasan pasien dengan minat menggunakan jasa pelayanan kesehatan di Puskesmas Dau Malang sebesar 0,414 dengan nilai signifikansi $(\rho)$ sebesar $0,003 \quad(\rho<0,05)$. Hal ini berarti hipotesa diterima dan menolak hipotesa nol (Ho). Dengan kata lain antara tingkat kepuasan pasien dengan minat menggunakan jasa pelayanan kesehatan di Puseksmas Dinoyo Malang. mempunyai keeratan hubungan yang cukup kuat dan signifikan (bermakna), Artinya semakin tinggi tingkat kepuasan pasien terhadap jasa pelayanan kesehatan di Puskesmas Dinoyo Malang. maka minat mereka untuk kembali menggunakan jasa pelayanan kesehatan di Puskesmas tersebut juga akan cenderung semakin tinggi. Sebaliknya semakin rendah tingkat kepuasan pasien terhadap jasa pelayanan kesehatan di Puskesmas Dinoyo Malang. maka minat mereka untuk kembali menggunakan jasa pelayanan kesehatan di Puskesmas tersebut juga akan cenderung semakin tinggi. Sebaliknya semakin rendah tingkat kepuasan pasien terhadap jasa pelayanan kesehatan di Puskesmas Dinoyo Malang, maka minat mereka untuk kembali menggunakan jasa pelayanan kesehatan di Puskesmas tersebut juga akan cenderung semakin rendah.

\section{PEMBAHASAN}

Berdasarkan karakteristik pekerjaan responden yang terbanyak adalah di dalam tabel pilihan Lain-Lain yaitu sebanyak (72\%) Responden, sedangkan lainnya cukup bervariasi seperti Swasta (26\%) dan PNS (2\%). Hal ini menggambarkan bahwa sebagian besar responden adalah pasien yang membayar tunai jasa pelayanan kesehatan yang bisa mendapatkan pelayanan kesehatan dimana saja sesuai dengan keinginannya.

Banyaknya responden yang berusia 21-30 tahun yaitu $(60 \%)$ yang merupakan usia dewasa awal yang mempunyai tingkat kematangan dan kemampuan dalam berpikir dan mengambil keputusan terhadap jasa pelayanan kesehatan. Ini sesuai dengan teori menurut Edwarson dalam Tjiptono (2006). Kepuasan merupakan tingkat perasaan seseorang setelah hasil yang dirasakan dengan harapannya, kualitas dari pelayanan dapat diukur dengan menentukan perbedaan antara apa yang diharapkan pengguna pelayanan dan bagaimana pengalamannya terhadap layanan tersebut. Untuk 
PROFESIONAL HEALTH JOURNAL

Volume2, No. 2, Juni 2021 (Hal. 101-111)

https://www.ojsstikesbanyuwangi.com/index.php/PHJ

mengukur kepuasan pasien pada suatu jasa atau produk yang ditawarkan menggunakan 5 dimensi kepuasan yaitu, Kepuasan Pasien terhadap dimensi bukti langsung, keandalan daya tanggap, jaminan dan empati (Tjiptono, 2006).

Bedasarkan hasil penelitian didapatkan jenis kelamin yang terbanyak adalah lakilaki yaitu sebanyak 24 orang dengan persentase (48\%), sedangkan perempuan sebanyak responden 26 orang dengan persentase $(52 \%)$. Meskipun mayoritas pasien adalah perempuan hal ini tidak menutup kemungkinan bahwa pasien LakiLaki beresiko lebih tinggi terserang penyakit.

Dari hasil penelitian diketahui mayoritas tingkat kepuasan responden sedang yaitu (52\%), hal ini dikarenakan pasien menilai fasilitas yang ada di Puskesmas cukup memadai, peralatan kedokteran yang digunakan cukup modern, petugas Puskesmas berpakaian dan berpenampilan rapi, serta sarana komunikasi yang ada cukup memadai.

Kepuasan Pasien Terhadap Dimensi Daya Tanggap tergolong sedang yaitu $72 \%$. Hal ini menunjukkan bahwa petugas di
Puskesmas Dinoyo-Malang cukup optimal untuk membantu para pasien dan memberikan pelayanan dengan cepat, serta mendengarkan dan mengatasi keluhan yang diajukan pasien, pasien mendapatkan informasi secara lengkap dan jelas tentang kondisi kesehatannya.

Kepuasan Pasien Terhadap Dimensi Jaminan, tergolong sedang yaitu $62 \%$, hal ini dikarenakan belum optimalnya petugas dalam memberikan jaminan keamanan dan kenyamanan dalam melakukan transaksi, kurangnya penjelasan petugas terhadap setiap tindakan. Selain itu kepuasan pasien juga dipengaruhi oleh faktor-faktor lain seperti pangkat, pendidikan, latar belakang sosial budaya, kedudukan sosial. Sedangkan menurut (Azwar,1996) kepuasan terhadap pelayanan kesehatan dipengaruhi oleh kepuasan terhadap pelayanan (medis, keperawatan, gizi, laboratorium, radiologi, administrasi), lingkungandan fasilitas yang tersedia (Azwar,1996).

Kepuasan Pasien Terhadap Dimensi Kehandalan tergolong sedang (60\%), hal ini menunjukkan bahwa petugas belum optimal dalam menempati janji dengan pasien, Hal ini sesuai dengan teori menurut 
PROFESIONAL HEALTH JOURNAL

Volume2, No. 2, Juni 2021 (Hal. 101-111)

https://www.ojsstikesbanyuwangi.com/index.php/PHJ

Tjiptono (1997), yang dapat mempengaruhi kepuasan terhadap pelayanan kesehatan seperti pendekatan dan perilaku petugas, mutu informasi yang diterima, prosedur perjanjian, waktu tunggu, fasilitas umum yang tersedia.

Kepuasan pasien terhadap dimensi empati tergolong sedang yaitu (88\%), hal ini dikarenakan belum optimalnya petugas dalam memberikan pelayanan (Tjiptono, 1997). Seseorang yang puas akan suatu jasa maka akan timbul suatu keyakinan bahwa jasa tersebut pantas untuk dipilih

\section{KESIMPULAN}

1. Berdasarkan hasil penelitian diketahui bahwa sebagian besar pasien mempunyai tingkat kepuasan pada pelayanan kesehatan oleh petugas di Puskesmas Dinoyo, Malang, yang tergolong Sedang (52\%).

2. Berdasarkan hasil penelitian diketahui bahwa sebagian besar pasien mempunyai minat pasien yang tergolong Sedang untuk menggunakan pelayanan jasa kesehatan di Puskesmas Dinoyo, Malang yang tergolong Sedang (78\%).

3. Pada hasil pengujian didapatkan $(\mathrm{r}=0,480$ dan $\rho=0,000)$ menunjukkan bahwa antara tingkat kepuasan pasien dengan minat menggunakan jasa pelayanan kesehatan di Puskesmas Dinoyo, Malang mempunyai hubungan yang signifikan, dengan arah korelasi yang positif, artinya semakin tinggi tingkat kepuasan pasien terhadap jasa pelayanan kesehatan di Puskesmas Dinoyo Malang, maka minat mereka untuk kembali menggunakan jasa pelayanan kesehatan di Puskesmas tersebut juga akan cenderung semakin tinggi, demikian sebaliknya.

\section{SARAN}

1. Bagi Instansi Puskesmas DinoyoMalang.

- Hasil penelitian ini dapat dijadikan sebagai bahan masukan dan pertimbangan bagi pihak manajemen Puskesmas dalam perencanaan dan evaluasi strategi yang berkaitan dengan upaya peningkatan mutu pelayanan Puskesmas

- Hendaknya Puskesmas DinoyoMalang memberikan pelatihan atau training pada kepada Sumber Daya Manusia yang ada, agar 
PROFESIONAL HEALTH JOURNAL

Volume2, No. 2, Juni 2021 (Hal. 101-111)

https://www.ojsstikesbanyuwangi.com/index.php/PHJ

dapat meningkatkan sikap dan

mutu pelayanan yang berkualitas

2. Bagi Peneliti berikutnya.

- Hasil penelitian ini dapat dijadikan sebagai studi pendahuluan untuk mengembangkan penelitian lainnya terutama di bidang sumber daya manusia. Selain itu perlu dilakukan penelitian lanjutan dengan memperluas variabel yang diduga juga dapat mempengaruhi minat pasien menggunakan jasa pelayanan kesehatan, selain tingkat kepuasan pasien

\section{DAFTAR PUSTAKA}

Adisasmito, W,. 2009. Sistem Manajemen Rumah Sakit. Jakarta: PT. Raja Grafindo Persada

Yulinda. $2008 \quad$ "Responsivitas Pelayanan Publik di Puskesmas Berstandar ISO“ Studi pada Puskesmas Jeruk kecamatan Lakarsantri Surabaya

Maria, 2009 "Pengelolaan kepuasan Pelanggan dalam Pelayanan
Kesehatan” Skripsi Unpad

Bandung

Ali, lukman, 1996. Kamus Besar Indonesia, Edisi kedua Balai Pustaka, Jakarta

Amin, M. AL, Hariyanto, P., Efendi, A., \& Yanuar, A. (2018). TRIAS UKS TERHADAP UPAYA PENCEGAHAN KENAKALAN REMAJA PADA SISWATINGKAT SMA / MA Muhammad Al Amin, dkk . Efektifitas Pembinaan Kader Kesehatan PENDAHULUAN UKS merupakan usaha memberikan umur 16-19 th sebanyak 8 orang, 20-24 th pendidikan tetntang kesehat. l(1), 27-38. https://www.ojsstikesbanyuwa ngi.com/index.php/PHJ/article /view/95/81

Damayanti, F. E. (2019). Resiliensi Istri Tentara (TNI-AD) yang Tinggal di Asrama Ketika Suami Bertugas di Daerah Konflik. Profesional Health Journal, 1(1), 9-20.

Mahdalena. 2008 "Hubungan Kepuasan Pasien Dengan 
PROFESIONAL HEALTH JOURNAL

Volume2, No. 2, Juni 2021 (Hal. 101-111)

https://www.ojsstikesbanyuwangi.com/index.php/PHJ

Minat Menggunakan Jasa

Pelayanan Kesehatan" Skirpsi

Universitas Brawijaya Malang

Azwar, Azrul. 1996. Pengantar

Administrasi Kesehatan:

Edisi Ketiga. Binarupa

Aksara, Jakarta

Azwar, S. 2003 Sikap Manusia, teori dan pengukurannya. Edisi ke 2 pustaka pelajar. Yogyakarta

Umar H . 2005 Metode Riset

Perilaku Konsumen Jasa.

Cipta Ghalia, Jakarta

Imam, D. K. 2001 Gambaran

Tingkat Kepuasan Pasien

Terhadap Pelayanan

Keprawatan di Instalasi

Rawat Inap RSUD kabupaten

Buleleng Bali. Skripsi.

Universitas Barawijaya

Malang

Gerson R. F. 2002. Mengukur

Kepuasan Pelanggan :

Panduan Menciptakan

Pelayanan Bermutu. Penerbit PPM. Jakarta

Muninjaya A. A. 2004 Manajemen

Kesehatan, Edisi 2 EGC,

Jakarta
Stoner (1996). Manajemen, Jilid I.

PT Bhuana Ilmu Populer, Jakarta

Tjiptono F. 2006. Manajemen Jasa.

Andi, Yogyakarta

2000 Perspektif Manajemen

dan

pemasaran

Kontemporer.

Andi.

Yogyakarta

Umar H . 2003 Metode Riset

Perilaku Konsumen Jasa.

Cipta Ghalia, Jakarta

Supriyanto. 2001. Jurnal

Administrasi dan Kebijakan

Kesehatan. Jakarta.

Notoatmodjo, 2010. Metodologi Penelitian Kesehatan. Edisi Kedua. Rineke Cipta, Jakarta.

Nugroho, J. 2003. Perilaku Konsumen: Konsep dan Klasifikasi untuk Strategi dan Penelitan Pemasaran, Kencana. Jakarta

Nursalam. 2003. Konsep dan Penerapan Metodologi

Penelitian Ilmu Keperawatan. Jakarta: Salemba Medika

Nursalam. 2008. Konsep dan Penerapan Metodologi Penelitian Ilmu Keperawatan. Jakarta: Salemba Medika 
PROFESIONAL HEALTH JOURNAL

Volume2, No. 2, Juni 2021 (Hal. 101-111)

https://www.ojsstikesbanyuwangi.com/index.php/PHJ

Nursalam. 2013. Konsep dan

Penerapan Metodologi

Penelitian Ilmu Keperawatan.

Jakarta: Salemba Medika

Parasuraman. 1998. Servequal: $A$

Multiple-Item Scalefor

Measuring Consumer

Perception of Service Quality.

Journal Of Retailing. Boston.

Poerwadaminta. 1990. Kamus Besar

Bahasa Indonesia, Balai

Pustaka Jakarta. 